Haben Sie Fragen zur Abrechnung oder zur wirtschaftlichen Praxisführung? Als Leser der MMW können Sie sich an unseren Experten wenden: Helmut Walbert, Facharzt für Allgemeinmedizin und Betriebswirt aus Würzburg.

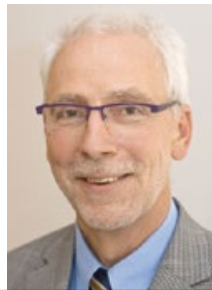

Helmut Walbert

Allgemeinarzt,

Medizinjournalist und

Betriebswirt Medizin

\title{
Ist ein Influenza-Test ein sinnvolles Angebot?
}

$?$

Dr. J. G., Hausarzt-Internist, Westfalen-Lippe: Die Grippesaison ist da. Wir wollen in diesem Jahr einen Influenza-Test vorhalten, um vor allem in frühen Verdachtsfällen eine Entscheidungshilfe für den Einsatz antiviral wirksamer Medikamente zu haben. Ist das wirtschaftlich sinnvoll?

Antwort: Die Wirtschaftlichkeit für die Praxis ist aus der Ferne schwer zu beurteilen: Da es sich hier um eine Individuelle Gesundheitsleistung (IGeL)

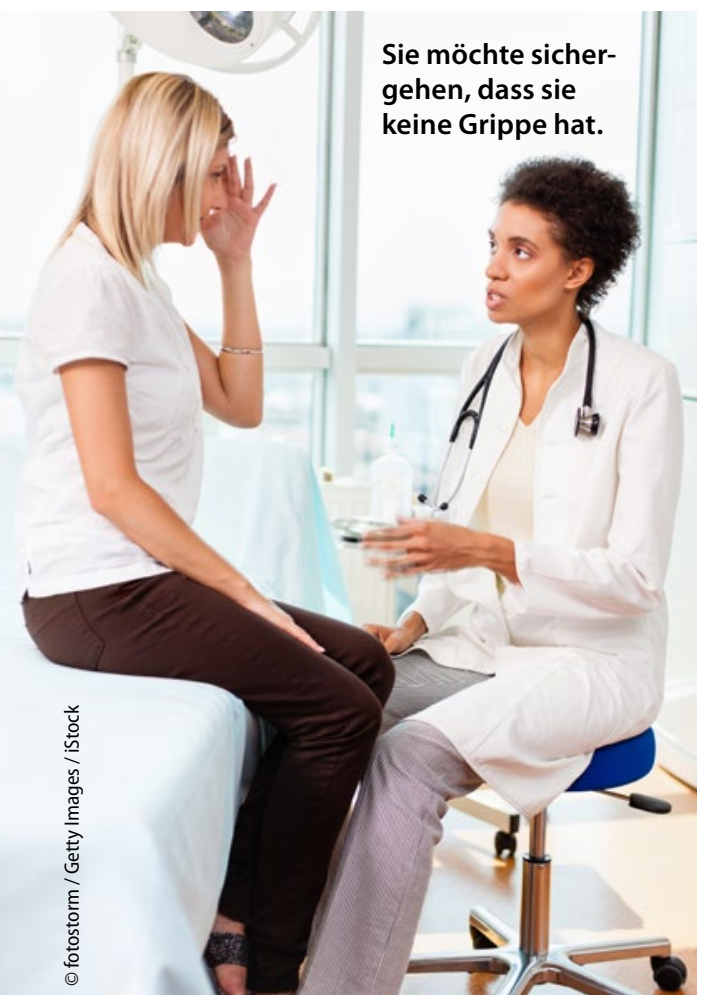

handelt, die der Patient zahlen muss, kommt es auf die Zusammensetzung und das Gesundheitsbewusstsein der Praxisklientel an. In einer Praxis mit zahlungskräftiger Klientel dürfte sich das Angebot auf jeden Fall lohnen.

Zum Einsatz für eine schnelle Therapieentscheidung in der Praxis kommen nur so genannte Point-of-care-Tests (POCT) infrage. Hier werden schnelle Ergebnisse (10-30 Minuten) mittels einer einfachen und wenig personalintensiven Methode gewonnen. Bei der Auswahl der Testkits sollten die saisonalen Influenzaviren beachtet werden. Auch die Angaben des Herstellers zur Sensitivität des Tests sind für die Zuverlässigkeit von Bedeutung. Die Spezifität ist in der Regel mit $80 \%$ bis über $95 \%$ relativ hoch.

Ein Problem in der Praxis kann die Beurteilung des Ergebnisses sein: Oft sind die Farbveränderungen nur schwach ausgebildet. So kann es zu falsch negativen Beurteilungen kommen. Hier spielt die Versiertheit der Medizinischen Fachangestellten (MFA) eine Rolle. In Untersuchungen konnte nach einem Training die Sensitivität um 30\% erhöht werden. Fazit für die Praxis: Am besten immer die gleiche MFA beurteilen lassen - und in Grenzfällen noch einmal selbst auf den Test schauen.

Liegt ein positiver Befund vor, ist es sinnvoll, in einem geeigneten Labor zusätzlich einen PCR-Test durchführen zu lassen. Das Ergebnis liegt in der Regel innerhalb von 24 Stunden vor. Dies ist für die Entscheidung zur Behandlung mit einem antiviralen Wirkstoff (z.B. Oseltamivir) zu spät, erspart aber die Meldung an das Gesundheitsamt. Die nachgewiesene Infektion mit einem Grippevirus gehört nämlich $\mathrm{zu}$ den meldepflichtigen Erkrankungen. Liegt nur ein positiver Schnelltest vor, muss die Praxis die Erkrankung melden; wird das Ergebnis durch einen positiven PCRTest bestätigt, ist das Labor zur Meldung verpflichtet.

Die Abrechnung erfolgt bei allen Patienten nach GOÄ:

- Nr. 1, Beratung, 10,72 Euro bei 2,3-facher Steigerung,

- Nr. 298, Entnahme und ggf. Aufbereitung von Abstrichmaterial zur mikrobiologischen Untersuchung, 5,36 Euro (2,3-fach),

- Nr. 4644, Ligandenassay zum Nachweis von Antigenen gegen Influenzaviren im Nativmaterial, inklusive Sachkosten für den Test, 16,76 Euro (1,15-fach).

Nun ist das normale Testkit eigentlich kein Ligandenassay - allerdings sagt der angesehene Kommentar Wezel/Liebold: „Hierunter kann analog auch der Influenza-Schnelltest abgerechnet werden, obwohl er nicht als Ligandenassay erbracht wird. Die hohen Reagenzienkosten rechtfertigen jedoch den analogen Ansatz."

Komplett ergibt die Leistung also 32,84 Euro. Ist eine glatte Summe von 32 oder gar 30 Euro gewünscht, erfordert eine korrekte Leistungsabrechnung eine entsprechende Veränderung des Faktors bei der Nr. 1 GOÄ. 